\title{
BIOCHEMICAL STUDIES ON HEPATITIS C VIRUS INFECTION
}

\author{
C. A. Abdel Malak; T. Mosa and M. Hawas \\ Biochemistry Division, Chemistry Department, \\ Faculty of Science Damietta, Mansoura \\ University, Egypt
}

\begin{abstract}
Hepatitis $C$ virus (HCV) infection is a major worldwide public health problem. The World Health Organization (WHO) estimates that 3\% (nearly 170 million people) of the world's population are chronically infected with $\mathrm{HCV}$ and that it accounts for around $20 \%$ of cases of acute hepatitis and $70 \%$ of cases of chronic hepatitis. Detection of HCV antigen in body fluids other than blood is important for assessing possible other routes of viral transmission. This is because body fluids other than blood might be potential sources of HCV infection. Serum and cerebrospinal fluid (CSF) samples of 25 meningitis patients infected with $\mathrm{HCV}$, serum and cord samples from 25 pregnant women infected with $\mathrm{HCV}$ in addition, serum and urine samples of 25 patients infected with $\mathrm{HCV}$ were included in this study. Also serum, CSF, cord and urine samples were collected from 30 healthy volunteers as negative controls. HCV antigen was detected in these body fluids using ELISA and western blotting techniques. Western blot analysis showing a single immunoreactive band in cord, CSF, urine and serum of HCV infected patients at 27-kDa. ELISA showed high degrees of sensitivity (92\%) and specificity (93.3\%). The antigen detection method showed high predictive values of positive (97.2\%) and negative (82.4\%).
\end{abstract}




\section{C.A. et al. Abdel Malak}

\section{INTRODUCTION}

HCV can cause acute or chronic hepatitis and is a health problem all over the world. It is one of the leading causes of cirrhosis and hepatocellular carcinoma (HCC), and is a common indication for liver transplantation. It is estimated that approximately 130-170 million people worldwide are infected with HCV. According to data from WHO community and blood donor surveys, the African, particularly Egypt and Eastern Mediterranean countries report the highest prevalence rates $(>10 \%)$. The rates of infection in the general population and the incidence of newly-acquired cases indicate an appreciable change in the epidemiology of the infection in recent years ${ }^{(1)}$. Unrecognized patients with $\mathrm{HCV}$ infection may transmit the virus to uninfected people. Although $\mathrm{HCV}$ is less prevalent since 1990 s in the Western world after improved blood-donor screening programs, needle-exchange facilities and education among intravenous drug users, it is still endemic in some regions, including African countries, Egypt. The virus is transmitted more frequently through infected blood or body fluids. Detection of antibodies against $\mathrm{HCV}$ is not a reliable method of diagnosing acute $\mathrm{HCV}$ infection since the appearance of antibodies against $\mathrm{HCV}$ can be delayed in up to $30 \%$ of patients at the onset of symptoms. Thus, the diagnosis of acute hepatitis $\mathrm{C}$ relies on the qualitative detection of HCV RNA, which may appear as early as 1-2 weeks after exposure quickly followed by highly elevated alanine aminotransferase ${ }^{(2)}$. Detection of $\mathrm{HCV}$ antigen in body fluids other than blood is important for assessing possible other routes of viral transmission, this is because body fluids other than blood might be potential sources of HCV infection ${ }^{(3)}$.

The aim of the present study was to detect $\mathrm{HCV}$ circulating antigen in some body fluids such as urine, cord and cerebrospinal fluid of infected individuals using some biochemical techniques. 


\section{SUBJECTS AND METHODS}

\section{Samples:}

Serum and cerebrospinal fluid (CSF) samples of 25 meningitis patients with $\mathrm{HCV}$ infection, serum and cord samples from 25 pregnant women infected with $\mathrm{HCV}$ in addition, serum and urine samples of 25 patients infected with HCV were included in this study. Also serum, CSF, cord and urine samples were collected from 30 healthy volunteers as negative controls. All samples were stored at $20{ }^{\circ} \mathrm{C}$ until analyses.

\section{SDS-PAGE and Western Blotting:}

These samples of selected patients were separated by SDSPAGE (3). Resolved samples were then electrotransfered onto the nitrocellulose filter $(0.45 \mu \mathrm{m}$ pore size, Sigma) in protein transfer unit (BioRad Laboratories, CA) according to ${ }^{(4)}$. The nitrocellulose filter was blocked using a blocking buffer composed of 5\% (w/v) dry milk dissolved in $0.05 \mathrm{M}$ tris-buffered saline (TBS), containing $0.15 \mathrm{M}$ $\mathrm{NaCl}, \mathrm{pH} 7.4$, rinsed in TBS, and incubated with anti-HCV polyclonal $\mathrm{Ab}$ diluted in blocking buffer with constant shaking overnight. The blots were washed three times ( $10 \mathrm{~min} /$ wash) in TBS followed by $2 \mathrm{hr}$ incubation with anti-rabbit IgG alkaline phosphatase conjugate (Binding site) diluted in TBS. The blots were then washed three times with TBS. The reaction was visualized by incubating the nitrocellulose filter and soaked in premixed 5-Bromo-9-Chloro-3Indolyl Phosphate / Nitro blue tetra-zolium BCIP/NBT alkaline phosphatase substrate (ABC Diagnostics, New Damietta City, Egypt). The reaction was stopped by distilled water after color development within $10 \mathrm{~min}$.

\section{Detection of HCV antigen using ELISA:}

After optimization of reaction condition, polystyrene microtiter plate were coated with $50 \mu \mathrm{l} /$ well of serum sample diluted 1: 100 in coating buffer ( $\mathrm{pH}$ 9.6) and incubated overnight at $4{ }^{\circ} \mathrm{C}$. After washing, $50 \mu 1 /$ well of 1: 100 diluted Specific anti-HCV IgG antibody in PBS-Tween 20 (PBS-T20) were added and incubated at $37{ }^{\circ} \mathrm{C}$ for 2 
h. After washing, $50 \mu \mathrm{l} /$ well of anti-rabbit IgG alkaline phosphatase conjugate (Binding site) diluted 1:300 in $0.2 \%(\mathrm{w} / \mathrm{v})$ BSA in PBS-T20, was added, and incubated for $1 \mathrm{~h}$ at $37^{\circ} \mathrm{C}$. The amount of coupled conjugate was determined by incubation with p-nitrophenyl phosphate substrate (Sigma). The reaction stopped by $\mathrm{NaOH}$ and the absorbance read at $490 \mathrm{~nm}$ using $\sum 960$ microplate autoreader (Metreiteck, Germany).

\section{Statistical analysis}

All statistical analyses were done by the statistical analysis program (SPSS) and considered statistically significant at a two-sided $P<0.05$. The diagnostic sensitivity, specificity, efficiency, and positive predictive values (PPV) and negative predictive (NPV) values were calculated as following:

\begin{tabular}{|l|l|l|l|}
\hline \multirow{2}{*}{$\begin{array}{c}\text { Reference } \\
\text { Test }\end{array}$} & \multicolumn{2}{|c|}{ Evaluated test } & \multirow{2}{*}{ Total } \\
\cline { 2 - 3 } & + ve & - ve & \\
\hline+ ve & True + ve (a) & False -ve (c) & $\mathbf{a}+\mathbf{c}$ \\
\hline - ve & False + ve (b) & True -ve (d) & $\mathbf{b}+\mathbf{d}$ \\
\hline Total & $\mathbf{a}+\mathbf{b}$ & $\mathbf{c}+\mathbf{d}$ & $\mathbf{a}+\mathbf{b}+\mathbf{c}+\mathbf{d}$ \\
\hline
\end{tabular}

Where:

Sensitivity $=a /(a+c) \times 100$.

Specificity $=d /(b+d) \times 100$.

Efficiency $=(a+d) /(a+b+c+d) \times 100$.

Positive predictive value $=\mathrm{a} /(\mathrm{a}+\mathrm{b}) \times 100$.

Negative predictive value $=d /(c+d) \times 100$. 


\section{RESULTS}

SDS-PAGE of serum and cord samples from patients infected with HCV and healthy individuals:

The resolved bands were identified in cord and serum after staining the gel by Coomassie Brilliant Blue R-250 dye, (Figure 1). It was found that the anti-HCV polyclonal $\mathrm{Ab}$ reacted against $\mathrm{HCV}$ antigen in cord and serum samples at molecular weight of $27 \mathrm{kDa}$.

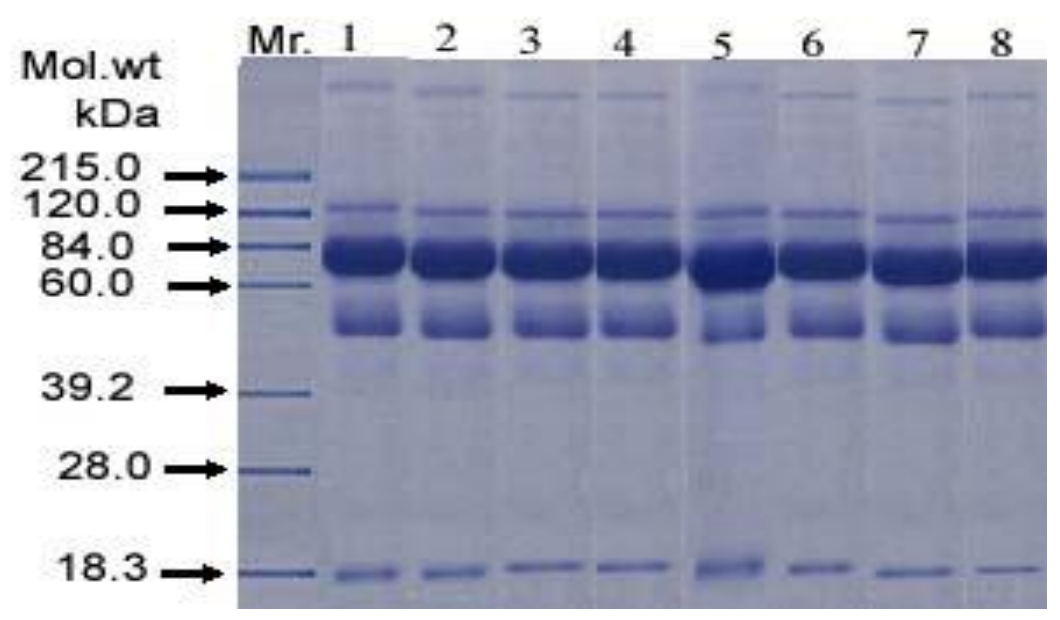

Figure 1: SDS-PAGE analysis of serum and cord samples from patients infected with HCV and healthy individuals. Lanes 1-2: Serum samples from healthy controls. Lanes 3-4: Cord samples from healthy controls. Lanes 5-6: Serum samples from patients infected with HCV. Lanes 7-8: Cord samples from virus patients infected with HCV. Molecular weight marker (Mr.) includes: Myosin $(215.0 \mathrm{kDa})$, phosphorylase B, (120.0 kDa), Bovine serum albumin $(84.0 \mathrm{kDa})$, Ovalbumin $(60.0 \mathrm{kDa})$, carbonic anhydrase $(39.2 \mathrm{kDa})$, trypsin inhibitor $(28.0 \mathrm{kDa})$, and lysozyme $(18.3 \mathrm{kDa})$. 
SDS-PAGE of serum and CSF samples from meningitis patients infected with $\mathrm{HCV}$ and meningitis patients without $\mathrm{HCV}$ infection:

The resolved bands were identified in CSF and serum after staining the gel by Coomassie Brilliant Blue R-250 dye, (Figure 2). It was found that the anti-HCV polyclonal $\mathrm{Ab}$ reacted against $\mathrm{HCV}$ antigen in CSF and serum samples at molecular weight of $27 \mathrm{kDa}$.

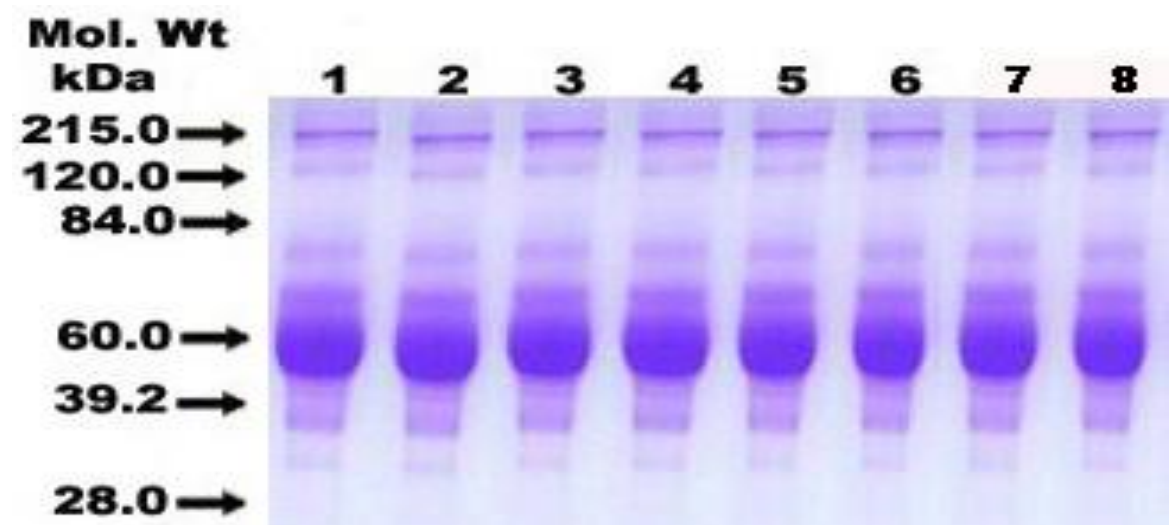

18.3

Figure 2: SDS-PAGE analysis of serum and CSF samples from meningitis patients infected with HCV and meningitis patients without HCV infection. Lanes 1-2: Serum samples from meningitis patients without HCV infection. Lanes 3-4: CSF samples from meningitis patients without HCV infection. Lanes 5-6: Serum samples from meningitis patients infected with HCV. Lanes 7-8: CSF samples from meningitis patients infected with HCV. Molecular weight marker (Mr.) includes: Myosin (215.0 kDa), phosphorylase B, (120.0 kDa), Bovine serum albumin $(84.0 \mathrm{kDa})$, Ovalbumin $(60.0 \mathrm{kDa})$, carbonic 
anhydrase $(39.2 \mathrm{kDa})$, trypsin inhibitor $(28.0 \mathrm{kDa})$, and lysozyme $(18.3 \mathrm{kDa})$.

SDS-PAGE of serum and urine samples from patients infected with $\mathrm{HCV}$ and healthy individuals:

The resolved bands were identified in urine and serum after staining the gel by Coomassie Brilliant Blue R-250 dye, (Figure 3). It was found that the anti-HCV polyclonal $\mathrm{Ab}$ reacted against $\mathrm{HCV}$ antigen in urine and serum samples at molecular weight of $27 \mathrm{kDa}$.

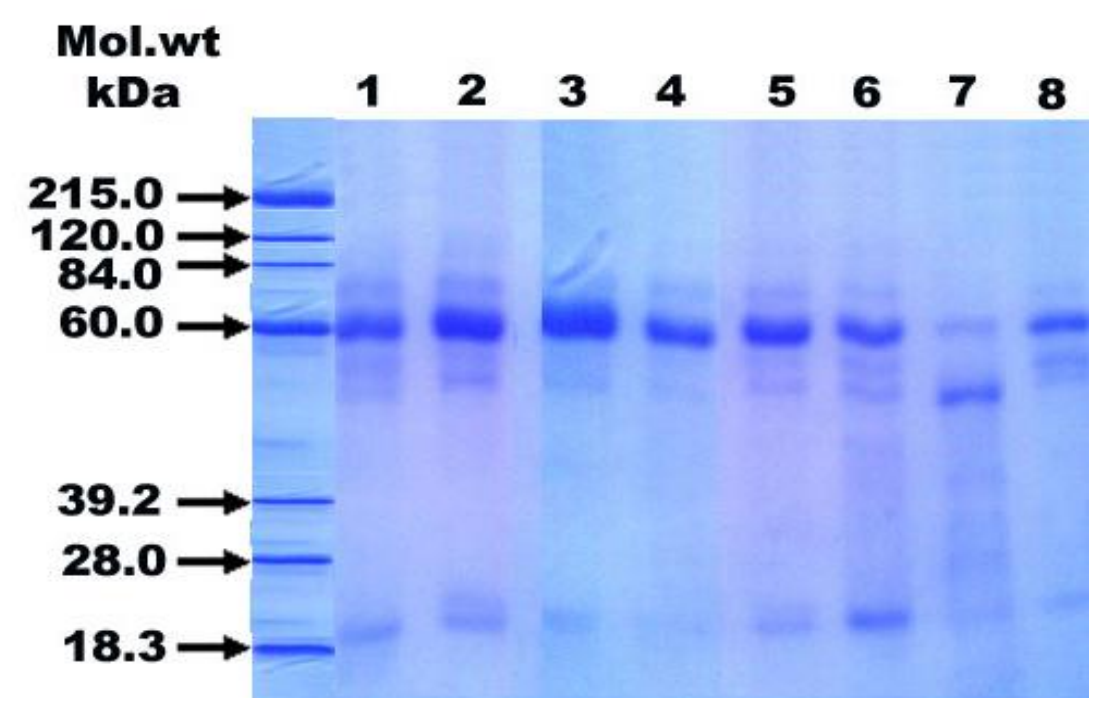

Figure 3: SDS-PAGE analysis of serum and urine samples from patients infected with HCV and healthy individuals. Lanes 1-2: Serum samples from healthy controls. Lanes 3-4: Urine samples from healthy controls. Lanes 5-6: Serum samples from patients infected with HCV. Lanes 7-8: Urine samples from patients infected with HCV. Molecular weight marker (Mr.) includes: Myosin $(215.0 \mathrm{kDa})$, phosphorylase B, $(120.0 \mathrm{kDa})$, Bovine serum albumin $(84.0 \mathrm{kDa})$, Ovalbumin $(60.0$ $\mathrm{kDa})$, carbonic anhydrase $(39.2 \mathrm{kDa})$, trypsin inhibitor $(28.0 \mathrm{kDa})$, and lysozyme (18.3 kDa). 


\section{Detection of HCV antigen in serum using ELISA:}

The cutoff value of ELISA was calculated as the mean ELISA optical densities of 16 serum samples from non-infected individuals \pm 3 standard deviation ( (i.e. $0.22 \pm[3 \times 0.020])=0.28)$, and serum samples from 8 infected patients showed optical densities above the cut off value. The optical densities (at $490 \mathrm{~nm}$ ) of 75 serum samples of $\mathrm{HCV}$ infected patients and 30 serum samples of healthy individuals tested for HCV antigen using ELISA. 69 and 2 sera were positive test showed ODS above the cutoff level for patients infected with HCV and healthy individuals; respectively, (Figure 4).

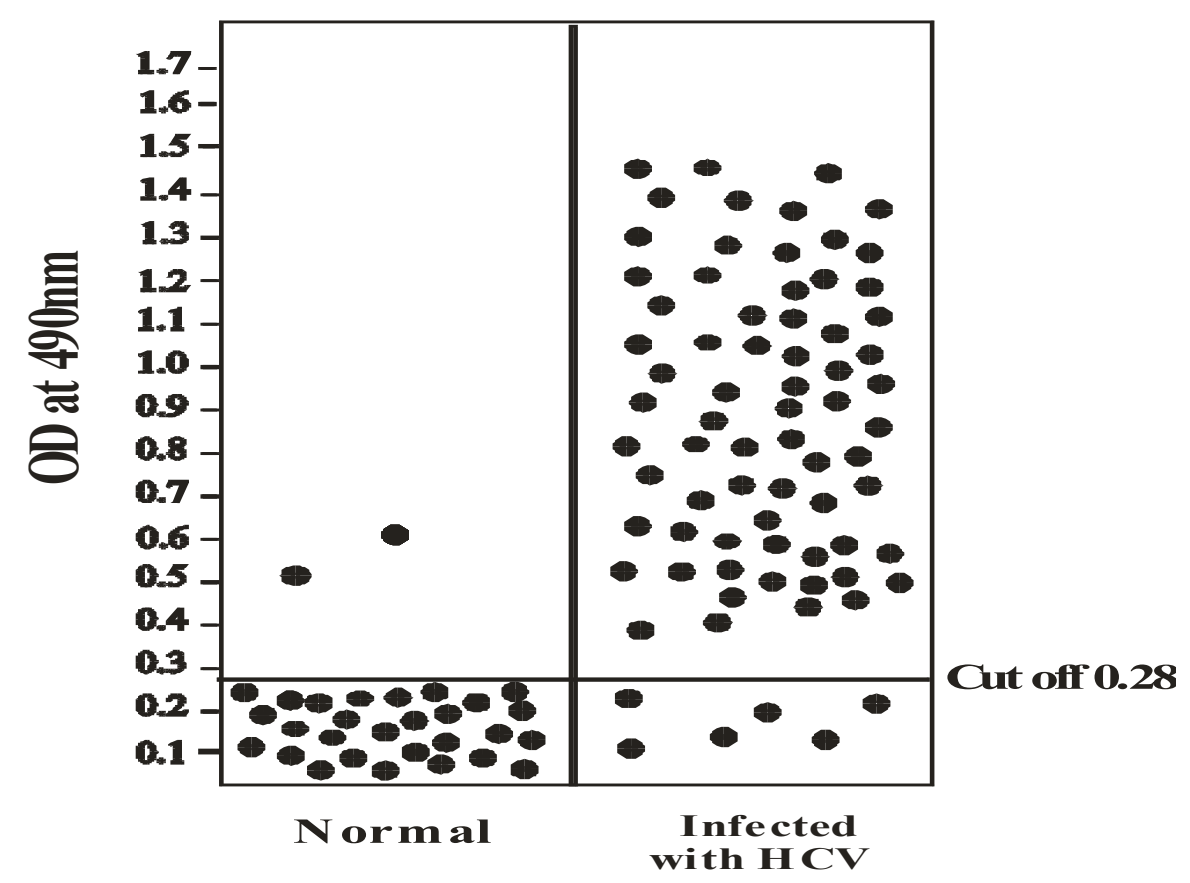

Figure 4: The cutoff value determination of ELISA above or below which the tested sample is considered positive or negative for HCV antigen. 
$\mathrm{HCV}$ antigen was detected in sera of $92 \%$ of total $\mathrm{HCV}$ infected patients and in sera of $6.7 \%$ of healthy individuals,

(Figure 5).

$\square$ HCV antigen

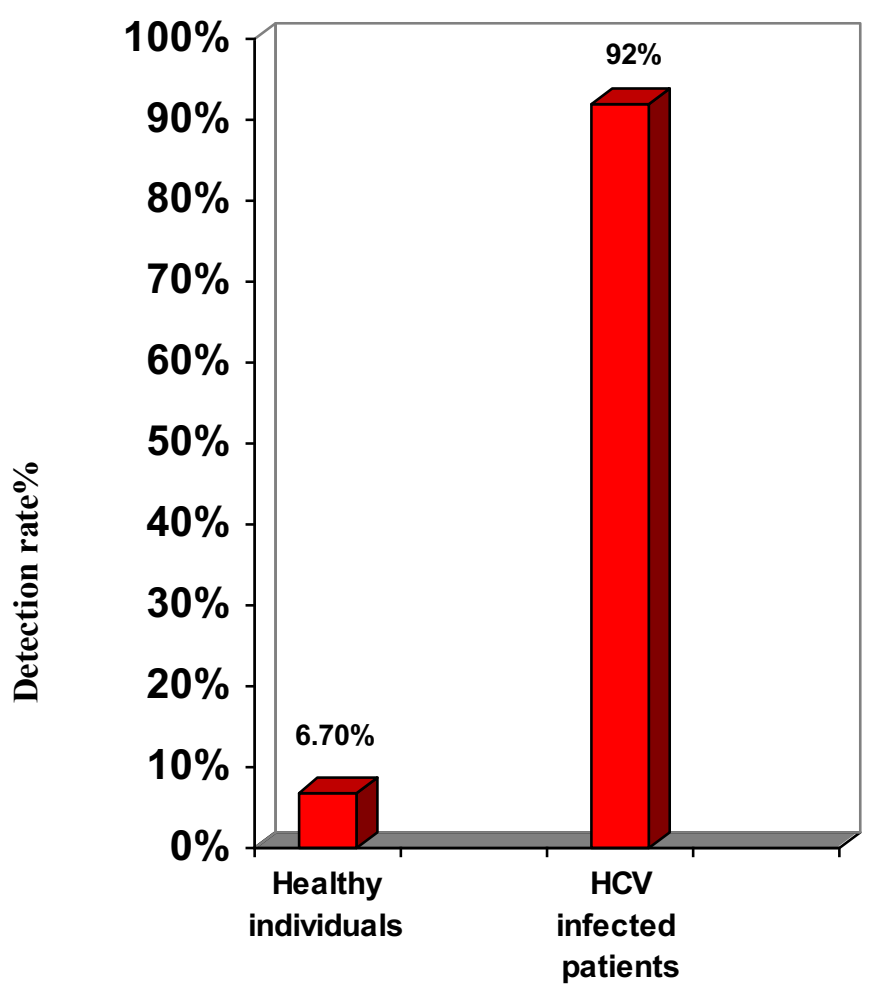

Figure 5: Detection rate of $\mathrm{HCV}$ antigen in $\mathrm{HCV}$ infected patients and healthy individuals using ELISA. 


\section{DISCUSSION}

World Health Organization considers HCV an epidemic, a "silent" epidemic because a patient living with HCV can be infected for decades before being discovered ${ }^{(6)}$. It is estimated that approximately 130-170 million people worldwide are infected with $\mathrm{HCV}$. Since the screening of blood and blood products for HCV began in the 1990s, blood transfusion has accounted for only a small percentage of adult $\mathrm{HCV}$ cases (about 3\%). Other routes of transmission include sexual, perinatal (from mother to infant at birth), familial (at low rates), and through health-care practices, including transmission by contaminated equipment or supplies, from patient to patient (at low rates), and through occupational exposure (at low rates). HCV infections are prevented by screening of the blood supply and reduction of contact with potentially contaminated fluids in health-care settings ${ }^{(7)}$. Detection of antibodies against $\mathrm{HCV}$ is not a reliable method of diagnosing acute $\mathrm{HCV}$ infection since the appearance of antibodies against $\mathrm{HCV}$ can be delayed in up to $30 \%$ of patients at the onset of symptoms. Thus, the diagnosis of acute hepatitis $\mathrm{C}$ relies on the qualitative detection of HCV RNA, which may appear as early as 1-2 weeks after exposure quickly followed by highly elevated alanine aminotransferase ${ }^{(2)}$. By using western blot analysis, it was found that, the specific anti-HCV polyclonal $\mathrm{Ab}$ reacted against $\mathrm{HCV}$ antigen in $\mathrm{CSF}$, cord, urine and serum samples at an apparent molecular weight of $27 \mathrm{kDa}$. Several authors use Western blot technique and other techniques in identification of $\mathrm{HCV}$ antigen in these samples. ${ }^{(8)}$ evaluated anti-HCV antibodies and HCV antigen in CSF and serum samples from 91 patients with meningitis using ELISA. The anti-HCV antibodies were detected in high percentages both in CSF samples (71\%) and in sera (90\%). Also, the HCV antigen was detected in about $60 \%$ of tested CSF and serum samples. On the other hand, ${ }^{(9)}$ detected HCV-RNA in 11 mothers and their newborns serum and peripheral blood mononuclear cells (PBMC) from venous blood and from the umbilical cord were collected during delivery using nested RT-PCR. HCV-RNA was detected in samples from umbilical cord in 7 (7/11) and in PBMC in $4(4 / 11)$ cases. Also, ${ }^{(10)}$ 
investigated HCV-RNA in oral fluid and urine of 80 Pakistani chronic HCV patients. HCV-RNA was detected in 31 (38.8\%) oral fluids and $10(12.5 \%)$ urine samples using RT-PCR in all 80 of the patients whose sera tested positive for HCV-RNA. In addition, in our study, $\mathrm{HCV}$ antigen was detected in 105 serum samples of HCV infected patients and 30 serum samples of healthy individuals using ELISA. ELISA showed high degrees of sensitivity (92\%) and specificity (93.3\%). (11) developed dot-ELISA assay for rapid and simple qualitative detection of the target $\mathrm{HCV}$ antigen in serum The antigen detection method showed high predictive values of positive $(99 \%)$ and negative $(90 \%)$. The developed method detected the HCV target antigen in $95 \%$ of serum samples from $\mathrm{HCV}$ infected individuals, with a specificity of $97 \%$ using sera of noninfected individuals in comparison with PCR test.

\section{ACKNOWLEDGMENTS}

The authors would like to thank Dr. Mohammed Mustafa at $\mathrm{R}$

\& D Dept., Biotechnology Research Center, New Damietta City, Egypt for his kind help.

\section{REFERENCES}

1- Baldo V, Baldovin T, Trivello $R$ and Floreani A. (2008): Epidemiology of HCV infection. Curr Pharm Des, 14(17): 164654.

2- Ozaras R and Tahan V. (2009): Acute hepatitis C: prevention and treatment. Expert Rev Anti Infect Ther.7(3):351-61.

3- Suzuki T, Omata K, Satoh T, Miyasaka T, Arai C, Maeda M, Matsuno T and Miyamura T. (2005): Quantitative detection of hepatitis $\mathrm{C}$ virus (HCV) RNA in saliva and gingival crevicular fluid of HCV-infected patients. J Clin Microbiol., 43(9):4413-7.

4- Laemmli, UK. (1970): Cleavage of structure proteins during the assembly of the head of bacteriophage T4. Nature, 51:227-680. 
5- Towbin H, Staehelin T and Gordon J. (1979): Electrophoretic transfer of proteins from polyacrylamide gels to nitrocellulose sheets; procedure and some applications. Biotechnology 1992, 24:145-149.

6- Fantini S, Zarelli L, Tomao P, Vonesch N, Signorini $S$ and Martini A. (2007): $\quad$ Virus C hepatitis: successful therapy in a health care worker. 29(3Suppl):763-4.

7- Major M, Rehermann B and Feinstone SM. (2001): Hepatitis C viruses. In Fields Virology. D. M. Knipe and P. M. Howley, eds. Philadelphia, PA: Lippincott Williams \& Wilkins, pp. 1127-1161.

8- Attallah AM and Ibrahim GG. (2004): Immunodetection of a hepatitis $\mathrm{C}$ virus (HCV) antigen and Thl/Th2 cytokines in cerebrospinal fluid of meningitis patients. , J Immunoassay Immunochem. 25(4):313-20.

9- Aniszewska M, Kowalik-Mikołajewska B, Pokorska-Lis M, Pawełczyk A, Radkowski M and Cianciara J. (2007): Motherto-infant HCV transmission--rate and course of HCV infection in children. Epidemiol., 61(1):7-15.

10- Shafique M, Ahmad N, Awan FR, Mustafa T, Ullah M and Qureshi JA. (2009): Investigating the concurrent presence of $\mathrm{HCV}$ in serum, oral fluid and urine samples from chronic HCV patients in Faisalabad, Pakistan. Arch Virol., 154(9):1523-7. Epub 2009 Aug 8.

11- Attallah AM, Ismail H, Tabll AA, Shiha GE and El-Dosoky I. (2003): A novel antigen detection immunoassay for field diagnosis of hepatitis C virus infection. J Immunoassay Immunochem. 2003; 24(4):395-407. 